\title{
Kajian Eksperimental Pengaruh Jarak Medan Magnet 2500 Gauss Dengan Karburator Terhadap Mesin Otto
}

\author{
Kostrawan K. ${ }^{1}$, Syahril Gultom ${ }^{2}$, Tulus B. Sitorus ${ }^{3}$, Terang UHS Ginting ${ }^{4}$, Dian M. Nasution ${ }^{5}$ \\ 1,2,3,4,5 Departemen Teknik Mesin, Fakultas Teknik, Universitas Sumatera Utara \\ Email: kostrawankaban@yahoo.com
}

\begin{abstract}
ABSTRAK
Krisis energi pada saat ini sudah dirasakan pada beberapa negara, mereka berlomba-lomba untuk mengadakan penghematan dan pemakaian energi yang tepat diberbagai bidang. Salah satu metode yang saat ini dikembangkan adalah magnetasi bahan bakar. Cara kerjanya adalah dengan memagnetasi bahan bakar premium yang mengalir menuju karburator pada saluran bahan bakarnya terlebih dahulu dengan menggunakan semacam alat yang mengandung kekuatan magnet tertentu. Medan magnet permanen yang cukup kuat pada molekul hidrokarbon yang bersifat diamagnetik akan menyebabkan reaksi penolakan antar molekul hidrokarbon sehingga terbentuk jarak yang optimal antara molekul hidrokarbon. Aktifitas molekular yang meningkat akibat medan magnet akan menyebabkan pengelompokan molekular terpecah. Oksigen akan lebih mudah bereaksi dengan masing-masing molekul hidrokarbon yang tidak lagi berada dalam kelompok, sehingga menghasilkan pembakaran yang lebih sempurna dan penurunan gas buang hasil pembakaran. Adapun tujuan dari penelitian yang dilakukan adalah untuk melihat persentase konsumsi bahan bakar yang paling efektif pada mesin bensin generator set dengan menggunakan 2500 gauss jarak $15 \mathrm{~cm}$ dan $30 \mathrm{~cm}$ dengan bahan bakar premium. Prosedur pengujian dengan bahan bakar premium yaitu pasang magnet di selang bahan bakar paling dekat dengan karburator dan dengan jarak $15 \mathrm{~cm}$ dan $30 \mathrm{~cm}$ untuk variasi medan magnet dan lepas magnet untuk pengujian tanpa magnetasi. Nyalakan bola lampu untuk melakukan variasi daya mesin. Data yang diperoleh dari pembacaan langsung alat uji mesin generator set 4langkah merk PAUS tipe PS2700 melalui unit instrumentasi dan perlengkapan yang digunakan pada saat pengujian adalah Putaran (rpm), Tegangan (volt) dan Kuat arus (A) dan Konsumsi bahan bakar. Dari hasil pengujian dan perhitungan yang telah dilakukan didapat bahwa penggunaan magnetasi dapat menurunkan konsumsi sampai $10.8108 \%$ dan meningkatkan effisiensi thermal rata-rata sampai $10.073 \%$.
\end{abstract}

Kata kunci : magnetasi, premium.

\section{PENDAHULUAN}

Krisis energi pada saat ini sudah dirasakan pada beberapa negara, mereka berlomba-lomba untuk mengadakan penghematan dan pemakaian energi yang tepat diberbagai bidang. Penghematan ini juga digalakkan dibidang otomotif yang terus berkembang. Pada saat ini energi yang digunakan pada kenderaan dengan menggunakan bahan bakar tidak semuanya dipakai untuk kinerja kendaraan tersebut, masih ada energi yang terbuang sia-sia.

Ketidaksempurnaan pembakaran menimbulkan efek negatif pada mesin, diantaranya laju konsumsi bahan bakar dan kadar emisi gas buang yang tinggi. Pembakaran baru dapat dikatakan mendekati sempurna jika kedua kondisi tersebut dapat ditekan semaksimal mungkin, yang berarti hemat dalam pemakaian bahan bakar dan rendahnya emisi gas buang.

Salah satu metode yang saat ini dikembangkan adalah magnetasi bahan bakar. Cara kerjanya adalah dengan memagnetasi bensin yang mengalir menuju karburator pada saluran bahan bakarnya terlebih dahulu dengan menggunakan semacam alat yang mengandung kekuatan magnet tertentu. Pada saat ini telah beredar dipasaran dengan nilai kandungan kekuatan medan magnet yang lebih tinggi dari terdahulu. 
Permasalahan magnetasi bahan bakar ini menjadi topik yang sedang hangat dibicarakan. Para produsen mengklaim bahwa produknya yang menggunakan asas magnetasi dapat menghemat pemakaian bahan bakar antara 20-30 \% dan menekan kadar gas polutan antara $40-70 \%[1]$.

\section{TINJAUAN PUSTAKA Motor Bensin}

Motor bensin atau mesin bensin dari Nikolaus Otto adalah sebuah tipe mesin pembakaran dalam yang menggunakan nyala busi untuk proses pembakaran, dirancang untuk menggunakan bahan bakar bensin. Motor bensin dilengkapi dengan busi dan karburator. Busi berfungsi sebagai penghasil loncatan api yang akan menyalakan campuran udara dengan bahan bakar, karena hal ini maka motor bensin disebut juga sebagai Spark Ignition Mesin. Sedangkan karburator merupakan tempat pencampuran udara dan bahan bakar [2].

Pada motor bensin, campuran udara dan bahan bakar yang dihisap ke dalam silinder dimampatkan dengan torak kemudian dibakar untuk memperoleh tenaga panas. Gas-gas hasil pembakaran dari bahan bakar akan meningkatkan suhu dan tekanan di dalam silinder, sehingga torak yang berada di dalam silinder akan bergerak turun-naik (bertranslasi) akibat menerima tekanan yang tinggi [2].

\section{Efek Magnetasi Pada Bahan Bakar Bensin}

Ketika bensin masih berada dalam tangkinya, molekul hidrokarbon yang merupakan penyusun utama bensin cenderung untuk saling tertarik satu sama lain, membentuk molekul- Medan magnet permanen yang cukup kuat pada molekul hidrokarbon yang bersifat diamagnetik akan menyebabkan reaksi penolakan antar molekul hidrokarbon (dechustering) sehingga terbentuk jarak yang optimal antara molekul hidrokarbon. Hal tersebut akan meningkatkan interaksi antara molekul hidrokarbon dengan oksigen [3].

Partikel-partikel atom yang membentuk molekul hidrokarbon tersebut akan terpengaruh oleh medan magnet yang ditimbulkan sehingga akhirnya akan menjadi semakin aktif dan arahnya akan sejajar (reorientasi) sesuai dengan arah dari medan magnet. Aktifitas molekular yang meningkat akibat medan magnet akan menyebabkan pengelompokan molekular terpecah. Oksigen akan lebih mudah bereaksi dengan masing-masing molekul hidrokarbon yang tidak lagi berada dalam kelompok, sehingga menghasilkan pembakaran yang lebih sempurna dan penurunan gas buang hasil pembakaran [3].

\section{Alat dan Bahan}

Alat

Alat yang dipakai dalam ekperimen ini terdiri dari :

1. Generator set bensin 4-langkah merk PAUS tipe PS2700.

2. Magnet untuk memagnetasi bahan bakar.

3. Digital Clamp Multimeter yang digunakan untuk mengukur tegangan dan kuat arus yang terjadi pada saat pengujian.

4. Tachometer untuk mengukur jumlah putaran permenit.

5. Alat uji emisi automotive emission analyzer SUKYOUNG SY-GA 401.

6. Kunci - kunci seperti kunci pas, kunci ring, kunci inggris, obeng, tang dan lain sebagainya.

7. Bola lampu yang digunakan sebagai pengatur daya yang akan di uji. 
8. Stop Wacth untuk mencatat berapa lama waktu konsumsi bahan bakar.

\section{Bahan}

Bahan yang menjadi objek pengujian ini adalah bahan bakar premium.

\section{Prosedur Pengujian}

Adapun prosedur pengujian yang dilakukan sebagai berikut:

1. Menghidupkan mesin dengan menarik starter yang terdapat pada mesin, memanaskan mesin selama 5 menit supaya mesin beroperasi dengan stabil.

2. Setelah mesin beroperasi stabil, maka mesin diuji konsumsi bahan bakar $50 \mathrm{ml}$.

3. Mencatat rpm melalui pembacaan tachometer.

4. Mencatat tegangan dan kuat arus dengan digital clamp meter.

5. Mencatat waktu konsumsi bahan bakar dengan stopwatch.

6. Melanjutkan pengujian mesin dari konsumsi bahan bakar $50 \mathrm{ml}$ sampai dengan 100 $\mathrm{ml}$.

7. Mengulang pengujian untuk variasi beban mesin.

\section{HASIL DAN PEMBAHASAN}

Daya

Setelah dilakukan analisa dari percobaan yang dilakukan maka hasil pengujian sebagai berikut:

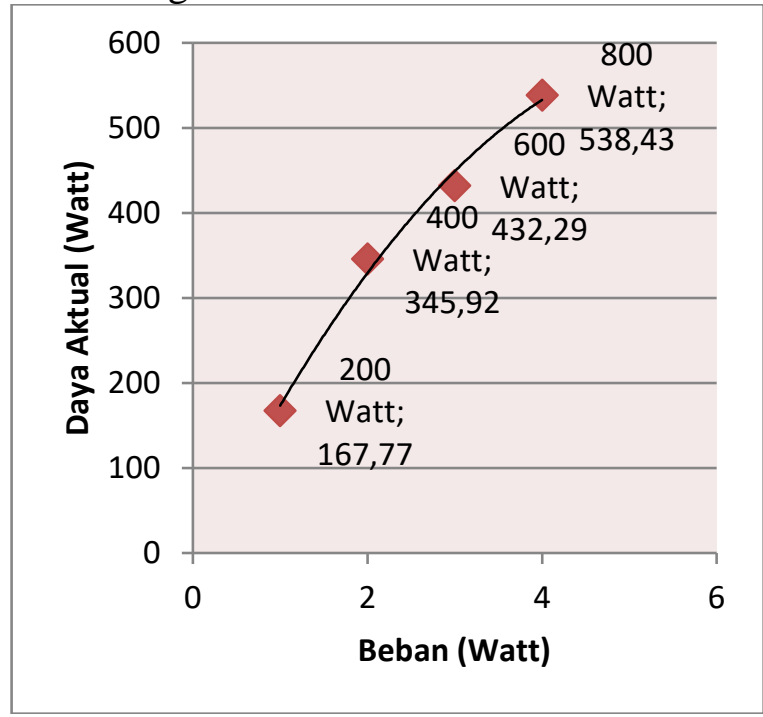

Gambar 1 Grafik hubungan Daya Lampu vs Daya Aktual tanpa magnet

Berdasarkan gambar 1 diatas, dapat dilihat bahwa Daya aktual yang diperoleh pada saat menggunakan bola lampu 200 Watt, 400 Watt, 600 Watt dan 800 Watt setelah diukur dengan menggunakan alat ukur clamp meter masing-masing rata-rata 167.77 Watt, 345.92 Watt , 432.296 Watt dan 538.43 Watt. 


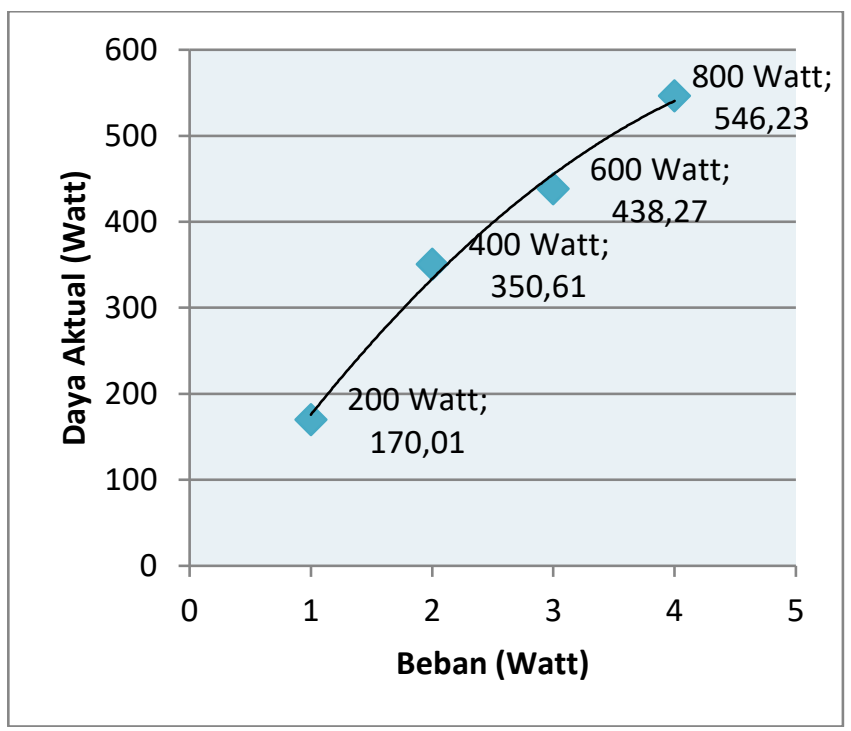

Gambar 2 Grafik hubungan Daya Lampu vs Daya Aktual dengan magnet 2500 Gauss jarak $0 \mathrm{~cm}$

Berdasarkan gambar 2 diatas, dapat dilihat bahwa Daya aktual yang diperoleh pada saat menggunakan bola lampu 200 Watt, 400 Watt, 600 Watt dan 800 Watt setelah diukur dengan menggunakan alat ukur clamp meter masing-masing rata-rata 167.77 Watt, 345.92 Watt, 432.296 Watt dan 538.43 Watt.

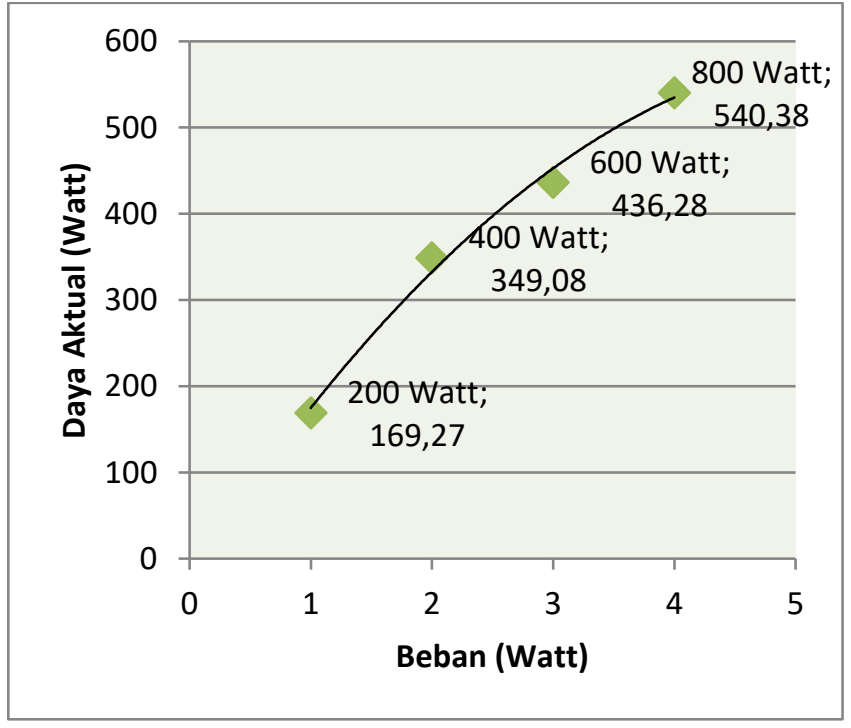

Gambar 3 Grafik hubungan Daya Lampu vs Daya Aktual dengan magnet 2500 Gauss jarak $15 \mathrm{~cm}$

Berdasarkan gambar 3 diatas, dapat dilihat bahwa Daya aktual yang diperoleh pada saat menggunakan bola lampu 200 Watt, 400 Watt, 600 Watt dan 800 Watt setelah diukur dengan menggunakan alat ukur clamp meter masing-masing rata-rata 169.27 Watt, 349.08 Watt, 436.28 Watt dan 540.38 Watt. 


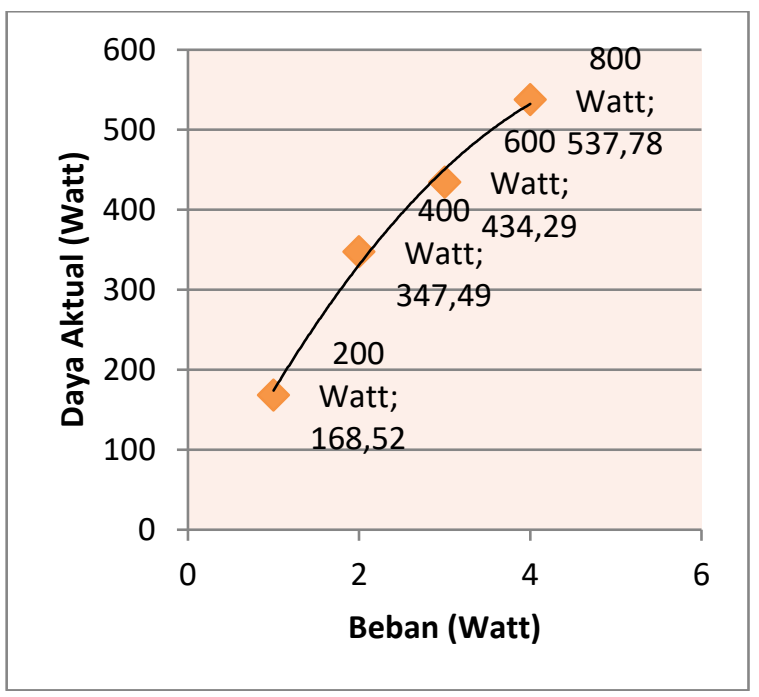

Gambar 4 Grafik hubungan Daya Lampu vs Daya Aktual dengan magnet 2500 Gauss jarak $30 \mathrm{~cm}$

Berdasarkan gambar 4 diatas, dapat dilihat bahwa Daya aktual yang diperoleh pada saat menggunakan bola lampu 200 Watt, 400 Watt, 600 Watt dan 800 Watt setelah diukur dengan menggunakan alat ukur clamp meter masing-masing rata-rata 168.52 Watt, 347.49 Watt , 434.29 Watt dan 537.78 Watt.

\section{Konsumsi Bahan Bakar Spesifik}

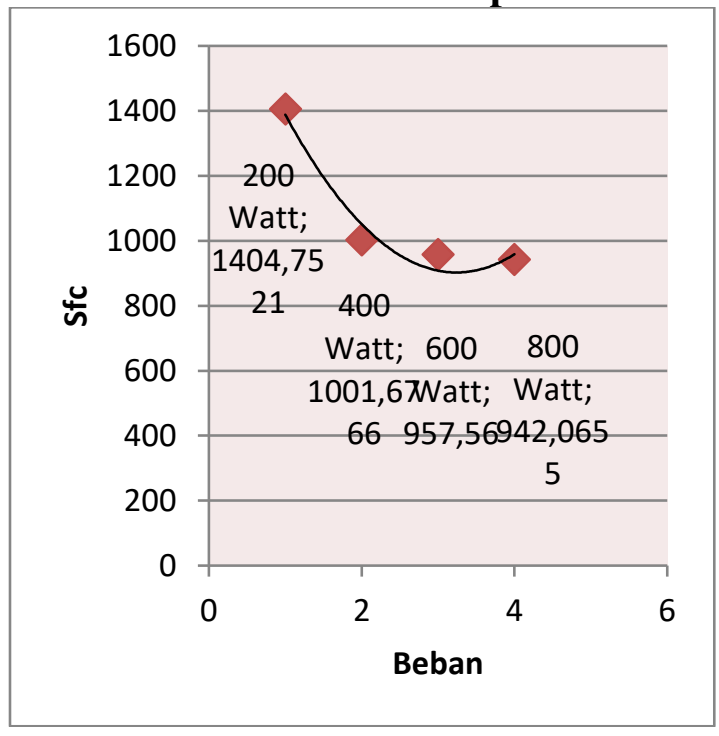

Gambar 5 Grafik hubungan Daya Lampu vs Sfc dengan tanpa magnet

Berdasarkan gambar 5 diatas, dapat dilihat bahwa Konsumsi bahan bakar spesifik (Sfc) yang diperoleh pada saat menggunakan bola lampu 200 Watt, 400 Watt, 600 Watt dan 800 Watt setelah konsumsi bahan bakar diukur dengan menggunakan stopwatch diperoleh Konsumsi bahan bakar spesifik $(S f c)$ rata-rata masing-masing 1404.7521 g/kW.h , 1001.6766 g/kW.h, 957.560 g/kW.h dan 942.0655 g/kW.h 


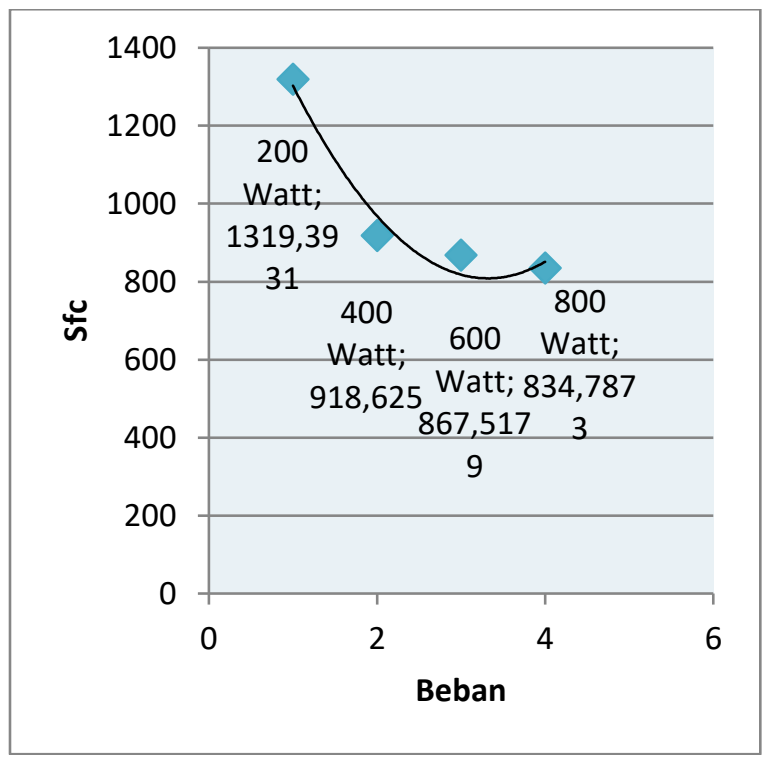

Gambar 6 Grafik hubungan Daya Lampu vs Sfc dengan magnet 2500 Gauss jarak $0 \mathrm{~cm}$

Berdasarkan gambar 6 diatas, dapat dilihat bahwa Konsumsi bahan bakar spesifik $(S f c)$ yang diperoleh pada saat menggunakan bola lampu 200 Wat, 400 Watt, 600 Watt dan 800 Watt setelah setelah konsumsi bahan bakar diukur dengan menggunakan stopwatch $\mathrm{r}$ diperoleh Konsumsi bahan bakar spesifik $\left(S f_{c}\right)$ rata-rata masing-masing $1319.3931 \mathrm{~g} / \mathrm{kW} . \mathrm{h}, 918.6250 \mathrm{~g} / \mathrm{kW} . \mathrm{h}, 867.5179 \mathrm{~g} / \mathrm{kW} . \mathrm{h}$ dan $834.7873 \mathrm{~g} / \mathrm{kW} . \mathrm{h}$

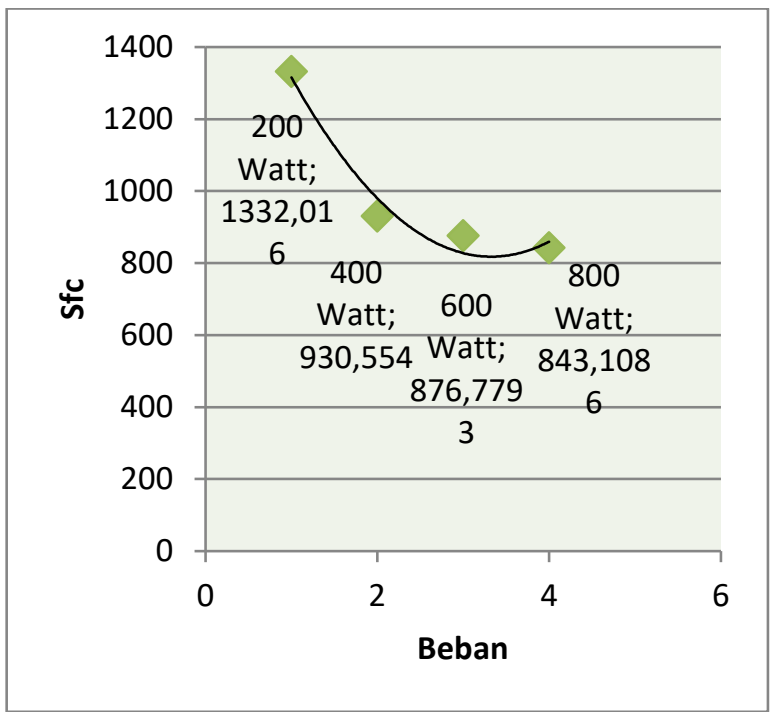

Gambar 7 Grafik hubungan Daya Lampu vs Sfc dengan magnet 2500 Gauss jarak 15 cm

Berdasarkan gambar 7 diatas, dapat dilihat bahwa Konsumsi bahan bakar spesifik $(S f c)$ yang diperoleh pada saat menggunakan bola lampu 200 Wat, 400 Watt, 600 Watt dan 800 Watt setelah setelah konsumsi bahan bakar diukur dengan menggunakan stopwatch $\mathrm{r}$ diperoleh Konsumsi bahan bakar spesifik $(S f c)$ rata-rata masing-masing 1332.016 g/kW.h , 930.554 g/kW.h, 876.7793 g/kW.h dan 843.1086 g/kW.h 


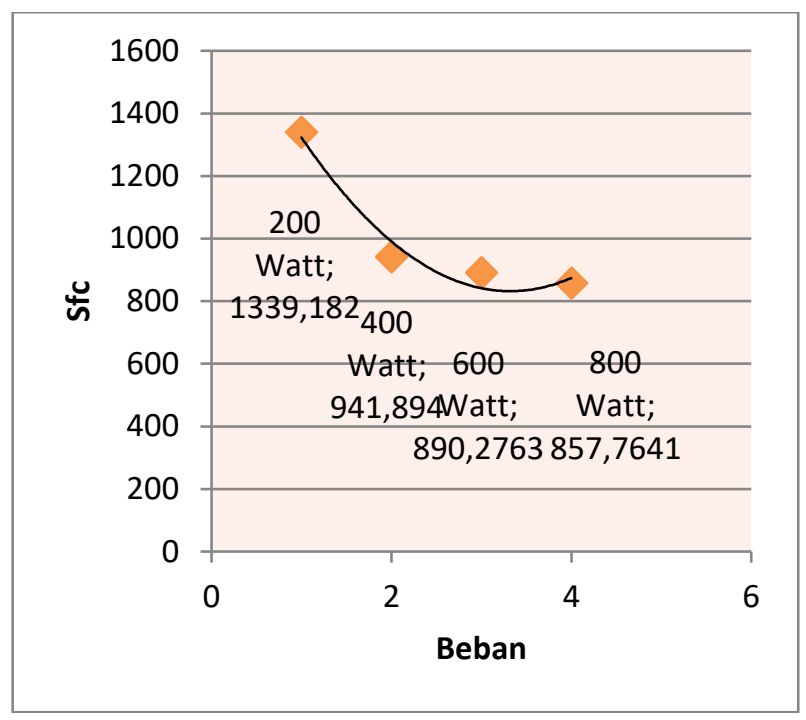

Gambar 8 Grafik hubungan Daya Lampu vs Sfc dengan magnet 2500 Gauss jarak $30 \mathrm{~cm}$

Berdasarkan gambar 8 diatas, dapat dilihat bahwa Konsumsi bahan bakar spesifik (Sfc) yang diperoleh pada saat menggunakan bola lampu 200 Wat, 400 Watt, 600 Watt dan 800 Watt setelah setelah konsumsi bahan bakar diukur dengan menggunakan stopwatch $\mathrm{r}$ diperoleh Konsumsi bahan bakar spesifik $\left(S f_{c}\right)$ rata-rata masing-masing 1339.182 g/kW.h , 941.894 g/kW.h, 890.2763 g/kW.h dan 857.7641 g/kW.h

\section{Perbandingan Konsumsi Bahan Bakar}

Setelah dilakukan analisa dari percobaan yang dilakukan maka perbandingan konsumsi bahan bakar dapat dilihat sebagai berikut:

Tabel 5 Perbandingan Konsumsi Bahan Bakar Tanpa Magnet, Maget jarak $0 \mathrm{~cm}, 15 \mathrm{~cm}$ dan $30 \mathrm{~cm}$.

\begin{tabular}{||c|c||}
\hline $\begin{array}{c}\text { Posisi Magnet 2500 } \\
\text { Gauss }\end{array}$ & $\begin{array}{c}\text { Perbandingan } \\
\text { Konsumsi } \\
\text { Bahan Bakar } \\
(\%)\end{array}$ \\
\hline Magnet jarak 0 cm & 10.15 \\
\hline Magnet jarak $15 \mathrm{~cm}$ & 9.5 \\
\hline Magnet jarak $30 \mathrm{~cm}$ & 8.47 \\
\hline
\end{tabular}

Berdasarkan tabel 5 diatas, dapat dilihat bahwa perbandingan konsumsi bahan bakar terendah pada percobaan dengan magnet jarak $30 \mathrm{~cm}$ Watt sebesar $8.47 \%$, sementara perbandingan konsumsi bahan bakar tertinggi pada percobaan dengan magnet jarak 0 cm sebesar $10.15 \%$.

\section{KESIMPULAN}

Kesimpulan yang dapat diambil dari penelitian dan pengujian yang telah dilakukan adalah :

1. Magnetasi bahan bakar premium dengan pemasangan magnet pada saluran bahan bakar terbukti memberikan efek pembakaran yang lebih sempurna untuk kondisi 
mesin yang sama. Hal ini dapat dilihat pada penurunan konsumsi bahan bakar, menaikkan daya dan penurunan konsumsi bahan bakar spesifik saat menggunakan magnet pada saluran bahan bakar.

2. Magnetasi bahan bakar premium dengan menggunakan magnet 2500 Gauss dengan jarak paling dekat terhadap karburator memberikan efek pembakaran yang lebih sempurna dibandingkan dengan magnet 2500 Gauss jarak $15 \mathrm{~cm}$ dan magnet 2500 Gauss jarak $30 \mathrm{~cm}$.

3. Efek Magnetasi bahan bakar premium maksimun pada saat menggunakan magnet 2500 Gauss dengan beban bola lampu 200 watt, 400 watt, 600 watt dan 800 watt.

- Daya aktual maksimum rata-rata, masing-masing 170.01 watt, 350.61 watt, 438.27 watt dan 546.23 watt.

- Penurunan konsumsi bahan bakar spesifik rata-rata, masing-masing 1319.33 g/kW.h, 918.625 g/kW.h, 867.5179 g/kW.h dan 834.7873 g/kW.h.

- Penurunan konsumsi bahan bakar rata-rata mencapai $4.8223 \%, 7.043 \%$, $8.3498 \%$ dan $10.0937 \%$.

\section{Saran}

1. Perlu diadakan lagi kajian yang lebih baik dalam mengenai bahan bakar premium dengan magnet sehingga diperoleh hasil yang lebih baik.

2. Untuk memperoleh hasil lebih baik, gunakan mesin yang lebih stabil.

3. Untuk mendukung kelancaran dan akurasi hasil pengujian sebaiknya dilakukan pemeriksaan dan kalibrasi terhadap instrumentasi dan alat ukur setiap kali pengujian dilakukan.

\section{DAFTAR PUSATAKA}

[1]Sudrajad, Agung. Menghemat Bahan Bakar Dengan Magnet Portabel, Universitas Darma Persada, Jakarta, 2006.

[2] Arends. BPM. And Berenschot. H, Motor Premium, Penerbit Erlangga, Jakarta, 1980.

[2] Irvan et al 2017 IOP Conf. Ser.: Mater. Sci. Eng. 206012028

[3]F. Ariani et al 2017 IOP Conf. Ser.: Mater. Sci. Eng. 277012045

[4]Pulkrabek, Williard. Machinering Fundamentals Of The Internal Combustion Mesin, Upper Suddel River, New Jersey, 07458.

[5]Heywood, Jhon B., Internal Combustion Mesin Fundamentals, McGrawHill,Inc., New York, 1998.

[6]J Arjuna et al 2018 IOP Conf. Ser.: Mater. Sci. Eng. 309012088

[7]Pudjanarsa, Astu. Dan Nursuhud, Djati, Mesin Konversi Energi, Penerbit Andi, Yogyakarta, 2006. 